\title{
Transformasi Perguruan Tinggi Keagamaan Islam Indonesia
}

\author{
Mujahidah* \& Ismail Suardi Wekke** \\ *Institut Agama Islam Negeri (IAIN) Parepare, Sulawesi Selatan \\ **Sekolah Tinggi Agama Islam Negeri (STAIN) Sorong, Papua Barat \\ *idhasuher@gmail.com **ismail@stain-sorong.ac.id \\ Presentasi Dalam \\ Seminar Nasional Kepemimpinan Transformatif \\ Forum Dosen Indonesia DPD Papua Barat \& Pasca Sarjana STAIN Sorong \\ Sorong, 26 Mei 2019
}

\begin{abstract}
ABSTRAK
Perguruan tinggi bukan saja menjadi sarana transformasi pengetahuan tetapi juga menjadi dinamisator masyarakat. Perguruan tinggi keagamaan Islam yang tersebar dari Banda Aceh sampai ke Jayapura sekaligus menjadi sarana pengembangan masyarakat. Pelbagai bentuk program yang dijalankan dalam rangka menunjukkan bentuk lebih teknis dari moderasi Islam. Pengembangan keilmuan termasuk pembukaan jurusan-jurusan yang variatif memberikan keleluasaan mahasiswa untuk belajar ilmu secara teknis. Makalah ini menunjukkan bahwa perguruan tinggi keagamaan Islam turut mengembangkan program-program yang tidak berfokus pada perguruan tinggi. Namun pada saat yang sama terdapat tantangan yang perlu diatasi sehingga pengembangan pendidikan tinggi keagamaan Islam tidak hanya pada lembaga negeri tetapi juga swasta.
\end{abstract}

Kata Kunci: Moderasi Islam, Perguruan Tinggi, Pendidikan Tinggi

\section{Pendahuluan}

Husaini (2006) mengemukakan bahwa perguruan tinggi keagaman Islam jutsru menjadi alat hegemoni Barat-Eropa. Pandangan ini tidak didasarkan pada observasi dan data yang yang komprehensif. Bisa jadi pandangan itu muncul jikalau hanya mendapatkan data sebagian saja. Pendidikan tinggi keagamaan justru menjadi wadah pengembangan keagamaan (Wekke, Hermawanto \& Ashrori, 2016). Bahkan Perguruan Tinggi sebagai salah satu elemen dalam Sistem Pendidikan Nasional mempunyai tanggungjawab dalam mencerdaskan kehidupan bangsa dan mewujudkan visi Indonesia 2030 untuk menciptakan masyarakat yang maju, sejahtera, mandiri dan berdaya saing tinggi. Untuk mewujudkan masyarakat yang memiliki daya saing tinggi dalam kancah internasional, Perguruan Tinggi termasuk Perguruan Tinggi Keagamaan Islam (PTKI) dituntut untuk menghasilkan lulusan yang berkualitas serta mampu 
memberikan tawaran solusi terhadap berbagai masalah kemanusiaan dan kebangsaan (Tilaar, 1998).

Perkembangan PTKI dengan istilah yang sebelumnya digunakan yaitu Perguruan Tinggi Agama Islam (PTAI) secara kuantitatif mengalami peningkatan, bahkan terakhir sudah dilantik rektor Universitas Islam Internasional Indonesia. Ini menjadi PTKI ke-60. Berdasarkan data pada tahun 2010, jumlah Perguruan Tinggi Agama Islam Negeri (PTAIN) yang semula hanya satu kini sudah mencapai 50 Institusi. PTAIN saat ini terdiri dari 6 Universitas Islam Negeri (UIN), 12 Institut Agama Islam Negeri (IAIN) dan 32 Sekolah Tinggi Agama Islam Negeri (STAIN). Kecuali Provinsi Bali dan Nusa Tenggara Timur, semuanya sudah terdapat perguruan tinggi keagamaan Islam. Adapun Perguruan Tinggi Agama Islam yang berstatus swasta (PTAIS), tercatat sebanyak 461 Institusi yang tersebar di seluruh pelosok tanah air. Keberadaan Perguruan Tinggi termasuk Perguruan Tinggi Agama Islam (PTAI) mempunyai kedudukan dan fungsi penting dalam perkembangan suatu masyarakat (Muhaimin, 2015).

\section{Peran PTAI dalam Pembangunan}

Perguruan Tinggi Agama Islam sebagai lembaga pendidikan tinggi yang diakui eksistensinya dalam Sistem Pendidikan Nasional mempunyai tanggungjawab dalam mendukung pembangunan di Indonesia (Daulay, 2014). Berdasarkan tujuan pendidikan tinggi sebagaimana diatur dalam PP 60 Tahun 1999 dan misi Kementerian Agama, maka secara konstitusional tujuan Pendidikan Tinggi Islam antara lain;

Pertama, Menyiapkan peserta didik menjadi anggota masyarakat yang memiliki kemampuan akademik dan atau profesional yang dapat menerapkan, mengembangkan, dan atau memperkaya khazanah ilmu, teknologi, seni dan atau kebudayaan yang bernafaskan Islam.

Kedua, Mengembangkan dan menyebarkan ilmu pengetahuan, teknologi dan seni yang bernafaskan Islam dan atau kebudayaan Islam untuk meningkatkan taraf kehidupan masyarakat serta memperkaya kebudayaan nasional. 
Ketiga, Merumuskan, menyebarluaskan dan mendidikkan filosofi dan nilai-nilai agama Islam sehingga dapat digunakan oleh masyarakat sebagai parameter perilaku kehidupan, menjadi inspirator dan katalisator pembangunan, serta motivator terciptanya toleransi kehidupan beragama, serta kehidupan yang harmonis antar umat yang berbeda agama.

Peran PTAI di atas sejalan dengan "World Declaration on Higher Education for the Twenty First Century: Vision and Action" yang dikeluarkan oleh UNESCO. Isi deklarasi tersebut relevan dengan paradigma baru Perguruan Tinggi di Indonesia. Salah satu isi deklarasi tersebut menyebutkan bahwa misi dan fungsi Perguruan Tinggi adalah membantu untuk memahami, menafsirkan, memelihara, memperkuat, mengembangkan, dan menyebarkan budaya-budaya historis nasional, regional dan internasional dalam pluralisme dan keragaman budaya (Queiroz \& Figueiredo, 2016).

\section{Tri Dharma Perguruan Tinggi}

Proses perubahan sosial (social change) di masyarakat yang dinamis, menuntut agar kedudukan dan fungsi perguruan tinggi itu benar-benar terwujud dalam peran yang nyata. Pada umumnya peran Perguruan Tinggi itu diharapkan tertuang dalam pelaksanaan Tri dharma Perguruan Tinggi, yaitu : dharma pendidikan, penelitian, dan pengabdian pada masyarakat. Melalui dharma pendidikan, Perguruan Tinggi Agama Islam diharapkan melakukan peran pencerdasan masyarakat dan transmisi budaya.

Sementara Perguruan Tinggi Agama Islam melalui dharma Penelitian diharapkan melakukan temuan - temuan baru ilmu pengetahuan dan inovasi kebudayaan. Untuk membumikan dharma bakti ke masyarakat, Perguruan Tinggi Agama Islam diharapkan melakukan pelayanan masyarakat untuk ikut mempercepat proses peningkatan kesejahteraan dan kemajuan masyarakat. Melalui dharma pengabdian pada masyarakat ini, Perguruan Tinggi Agama Islam juga akan memperoleh feedback dari masyarakat tentang tingkat kemajuan dan relevansi ilmu yang dikembangkan Perguruan Tinggi itu. 
Peran PTAI (Perguruan Tinggi Agama Islam) juga bersifat multidimensi. PTAI dituntut untuk menjadi agen perubah dalam modus keagamaan masyarakat. PTAI ditantang untuk dapat mengembangan teologi "Unity in Diversity", sebagai landasan moralitas publik dalam kerangka Pancasila. PTAI hendaknya dapat mengambil peran penting dalam proses obyektivikasi nilai-nilai Pancasila ke dalam paradigma keilmuannya, terutama yang berkaitan dengan pengembangan prinsip ketuhanan dalam teori-teori agama publik. PTAI hendaknya juga mengambil peran aktif dalam mengembangkan riset, edukasi dan pelayanan yang berkaitan dengan landasan spiritualitas dalam mendorong atos kerja yang positif. Lulusan PTAI dengan wawasan agama yang lebih luas dan mendalam, hendaknya bisa memberikan pupuk kesuburan di tengah kegersangan kehidupan etis dan welas asih di tengah - tengah kehidupan publik (Fuaduddin, 2002).

\section{Keberadaan PTAI dalam Membangun Harmoni Kehidupan Beragama}

PTAI sebagai lembaga pendidikan tinggi Islam, memberikan kontribusi terhadap model keberagamaan masyarakat Muslim Indonesia. Studi Islam yang dikembangkan di PTAI tidak hanya mendukung model keberagamaan inklusif di kalangan masyarakat Muslim Indonesia, lebih dari itu juga mendorong terbentuknya kerukunan antar umat beragama di Indonesia. Teologi inklusif dirintis perkembangannya oleh Harun Nasution dengan membuka mata kuliah teologi Islam yang bercorak non mazhab dan bersemangat toleran. Konsep ini selanjutnya menjadi bagian dalam karya Nurcholis Madjid termasuk dalam pendirian Universitas Paramadina (Nasution, 1975; Madjid, 1997; Shihab, 1997). Bahkan Universitas Paramadina menjadi lembaga pendidikan yang menerima mahasiswa lintas iman dengan tetap fokus pada pembentukan sikap keagamaan (Sabri, Ikhsan \& Wekke, 2018).

Sedangkan konsep kerukunan antar umat beragama, telah dirintis perkembangannya oleh A. Mukti Ali (1988), baik semasa menjadi Menteri Agama maupun ketika mengajar di IAIN Yogyakarta. Sementara itu tentang sumbangan Muslim Indonesia tentang wacana Islamisasi ilmu pengetahuan juga tampak. Muslim Abdurrahman (1995) dengan konsepnya Islam transformatif mencoba 
menggagas penerjemahan nilai normatif Islam ke dalam sebuah ideologi transformasi. Kuntowijoyo dengan konsep ilmu sosial propetik adalah sebuah ide yang penting dalam proses pencarian konsep Islamisasi ilmu pengetahuan yang sesuai dengan proses perkembangan sejarah maupun budaya (Arifin, 2014). Di bidang lain, munculnya sarjana muslim semisal Azyumardi Azra (1994), dan Komaruddin Hidayat (2005), untuk menyebut beberapa orang, mengindikasikan keterlibatan muslim Indonesia dengan wacana keislaman terlebih dengan wacana global dunia.

Mewujudkan Islam Indonesia yang ramah dan damai, alumni PTAI tidak hanya harus memiliki dasar pengetahuan (basic competency) dalam bidang agama guna memenuhi harapan yang bersifat sosial. Lebih dari itu juga harus memiliki kualifikasi sebagai insan akademis. Tamatan PTAI dituntut memiliki wawasan teoritis dan keterampilan yang dibutuhkan dalam era globalisasi. Maka prakarsa pengembangan institusi dan juga penguatan kurikulum dilakukan secara berkala. Sejak 1997, semua kelembagaan Institut Agama Islam Negeri (IAIN) yang berada di daerah dengan status fakultas ditingkatkan menjadi sekolah tinggi. Kemudian dengan kebijakan yang konsisten antara 2000 sampai 2019, secara bertahap sekolah tinggi menjadi institute.

Khusus dalam bidang kehidupan keagamaan, terdapat sejumlah kecendrungan perubahan sosial yang perlu mendapatkan perhatian kalangan Perguruan Tinggi Agama Islam, diantaranya (Faududdin, 1999) :

1) Pembangunan khususnya kota-kota yang telah membawa perkembangan dan dinamika yang heterogen, komposisi penduduk semakin beragam karena semakin bertambahnya para pendatang baik dari daerah-daerah dipedalaman. Apabila mereka itu kurang mampu beradaptasi dengan tradisi dan budaya setempat, sehingga keragaman ini jika tidak mampu dikelola dengan baik maka pada waktunya akan berkembang kearah yang tidak menguntungkan. Ini harus didekati dengan Tri Dharma Perguruan Tinggi.

2) Masalah ekonomi masyarakat, khususnya yang terkait dengan pergeseranpergeseran hak pemilikan tanah, baik antara penduduk setempat maupun antara penduduk setempat dan pendatang, dapat mengarah kepada keresahan 
masyarakat apabila pergeseran hak kepemilikan itu atau pemanfaatan tanah itu kemudian ditenggarai berkaitan dengan simbol-simbol kelompok sosial, budaya, atau agama tertentu. Ini tentu perlu dikelola dengan baik dan juga harus didekati melalui Tri Dharma Perguruan Tinggi.

3) Tradisi atau kearifan local (local wisdom) yang secara turun temurun mentradisi dalam kehidupan. Dalam kehidupan masyarakat yang telah berfungsi dengan baik dalam membangun harmonis sosial perlu terus dikaji, diinventarisir, dianalisis hubungannya dengan nilai ajaran agama, dan disosialisasikan. Konsep-konsep seperti "kayuh baimbai" (kerjasama), "gawisabumi (gotong-royong), basusun sirih (kesetaraan), menyisir sisi tapih (introspeksi), rumah betang (kasih sayang dan persaudaraan), handep atau habaring hurung (gotong-royong), juga harus didekati dengan Tri Dharma Perguruan Tinggi. Secara khusus IAIN Kendari ada tahun 2017 melaksanakan International Conference on Islam and Local Wisdom (ICLaW). Pelaksanaan konferensi ini sebagai kewujudan pembahasan kearifan lokal dalam percakapan keilmuan secara luas.

4) Forum-forum komunikasi antar umat beragama yang merupakan bentuk kearifan lokal hasil kesepakatan zaman ini, juga perlu didekati Tri dharma Perguruan Tinggi.

5) Masalah kemiskinan akibat semakin kurangnya lahan hutan dan pertanian, dan perpindahan tenaga kerja tidak terampil dari desa ke kota sehingga menambah angka pengangguran dikota, serta bagaimana mekanisme yang ada dalam masyarakat mengatasi masalah-masalah itu, adalah juga hal yang perlu didekati dengan Tri dharma Perguruan Tinggi. Apalagi karena hal tersebut sebagian besar menyangkut warga masyarakat beragama Islam.

6) Masalah kebodohan dan keterbelakangan yang masih melilit sebagian masyarakat, baik karena pandangan dikotomis ilmu agama dan umum, maupun karena keterpencilan geografis atau kemiskinan, serta mekanisme sosial yang ada mengatasi hal itu, perlu didekati dengan Tridharma Perguruan Tinggi. 


\section{Program PTAI dalam Membangun Demokrasi}

Keberadaan Indonesia sebagai negara muslim terbesar di dunia dan pada saat yang sama dianggap sebagai negara demokratis terbesar ketiga di dunia. Hal ini menunjukkan realitas adanya korelasi positif antar umat Islam yang begitu besar dengan demokrasi. Ada kompatibilitas antara Islam dengan demokrasi di Indonesia. Kontribusi Perguruan Tinggi Agama Islam (PTAI) tidak bisa diabaikan. Sebab, PTAI berfungsi menjadi penjaga gawang keimanan umat, menjaga religiusitas umat Islam Indonesia (Fadjar, Zumar \& Dja'far, 1999)..

Di samping melahirkan sarjana - sarjana yang siap memasuki dunia kerja, peran paling fundamental PTAI yang sering tidak disadari adalah keberadaannya dalam menjaga keberagamaan umat Islam Indonesia, serta mempertahankan Islam yang moderat yang ada di Indonesia. Hal ini bahkan sudah diperankan sejak dulu dan akan terus dipertahankan dan diperbaiki agar umat Islam Indonesia tetap menjadi warga negara yang demokratis dan mampu menciptakan suasana kondusif untuk membentuk masyarakat madani.

Terciptanya masyarakat demokratis di Indonesia karena sumbangsi lembaga pendidikan Islam yang telah mendidik dan mengajarkan generasi muda Islam dengan ajaran - ajaran agama yang moderat dan toleran. PTAI berkontribusi signifikan dalam menciptakan infrastruktur yang kuat sehingga Indonesia tidak muda dipenetrasi oleh gerakan - gerakan radikal dan ekstremis. PTAI telah memainkan perannya sebagai cultural broker untuk menyongsong perubahan sosial dan globalisasi yang terjadi begitu cepat sehingga moderasi Islam bisa dipertahankan, keimanan umat terjaga dan tetap menciptakan SDM yang berwawasan ilmu pengetahuan dan teknologi yang tinggi dengan basis karakter yang beriman dan bertaqwa kepada Tuhan Yang Maha Esa.

\section{Problematika Pengembangan PTAI}

Secara kelembagaan PTAI telah memenuhi ketentuan dasar eksistensinya, sebab diproses melalui syarat dan mekanisme yang ditentukan oleh perundang-undangan. Tetapi dalam operasionalisasinya terdapat juga PTAI yang terhambat, tersendat bahkan terhenti, terutama dalam penyelenggaraan Program 
Studinya. Pada PTAI yang diselenggarakan oleh masyarakat, yakni PTAI Swasta (PTAIS), mayoritas berupa Program Studi Pendidikan Agama Islam, kemudian Program Studi tertentu dari Fakultas Syari'ah, Dakwah dan Ushuluddin.

Permasalahan yang dialami oleh PTAIS meliputi infrastruktur, mahasiswa, pembiayaan, proses akademik, dan kualitas lulusan. Dari segi inftastruktur, walaupun pada umumnya PTAIS telah memiliki kampus, namun bervariasi antara yang berada di tanah milik dilengkapi dengan bangunan dan sarana yang memadai, namun ada juga yang masih menyewa, atau di kampus sendiri namun sarananya masih sederhana dan terbatas. Kampus PTAIS yang berada di Pondok Pesantren sangat ideal, namun mahasiswa yang mondok di Pesantren terbatas jumlahnya. Kampus PTAIS rata - rata dilengkapi dengan Perpustakaan namun bervariasi antara yang banyak dan sedikit buku pustakanya. Sedangkan laboratorium, baik Micro Teaching, Komputer atau Bahasa, rata-rata masih terbatas, bahkan ada yang belum memiliki.

Dari segi mahasiswa, peminat Program Studi pada PTAI swasta masih belum memiliki daya sanding, sehingga kualitas input tidak bisa diseleksi. Hal ini disebabkan masyarakat lebih banyak yang berorientasi pada perguruan Tinggi Negeri dengan pilihan program studi yang beragam. Pada sisi ini, PTAI swasta belum mampu bersaing secara kuat dengan perguruan tinggi lainnya. Walaupun demikian, biaya yang relatif terjangkau dan juga keberadaan perguruan tinggi di daerah memberikan kesempatan bagi masyarakat untuk menempuh pendidikan. Mulai pula pengembangan perguruan tinggi dalam bentuk institut, dan juga status akreditasi yang sudah mencapai B.

Dampak dari kecilnya jumlah penerimaan mahasiswa maka mengakibatkan sulitnya pembiayaan PTAI swasta, sebab rata -rata pembiayaan PTAI swasta tergantung pada dana Sumbangan Pembinaan Pendidikan (SPP). Sedikit sekali, bahkan hampir bisa dikatakan tidak ada, PTAI swasta yang mempunyai sumber lain yang menjadi kiprah usahanya untuk membiayai program akademik. Bantuan dari Pemerintah belum terbuka, walau dari segi equity, harusnya Pemerintah menyetarakan anggaran bagi perguruan tinggi negeri dan swasta. Terdapat PTAI swasta yang secara berkala mendapat alokasi anggaran 
dari Pemerintah Daerah setempat, terutama yang secara historis kelembagaannya dibidani oleh birokrat setempat.

Berdasarkan problematika sarana yang terbatas, input mahasiswa yang kecil, jumlah biaya yang tidak memadai, berimplikasi pada problematika proses akademik. Dari segi kurikulum ditempuh pengurangan sks sampai batas yang limitatif, dari segi hari perkuliahan dikurangi jumlahnya perminggu, penerimaan dosen terbatas pada pemenuhan keperluan pokok, tidak mustahil terjadi penyederhanaan dalam proses perkuliahan dan ujian. Termasuk problematika penguasaan bahasa asing (Wekke, 2017). Dalam praktiknya, dharma penelitian mendapatkan porsi yang tidak sama dengan dua dharma lainnya, kecuali dalam penelitian skripsi yang dilakukan mahasiswa. Itupun mengalami tantangan dalam kaitan kejujuran akademik (Ardinansyah, Tenrisau, Aslim, \& Wekke, 2018). Begitu juga Kuliah Kerja Nyata atau yang sejenisnya sebagai salah satu program untuk dharma pengabdian kepada masyarakat, ditunaikan dalam porsi yang terbatas.

Perguruan tinggi keagamaan Islam mengalami tantangan secara global. Keberadaan perangkat digital, jika tidak dijadikan sebagai media pembelajaran akan mengalami ketertinggalan dan pada akhirnya ditinggalkan. Sebuah keperluan untuk mengintegrasikan pembelajaran dengan kondisi digital (Mulyono \& Wekke, 2018c). Paling awal yang perlu dijadikan sebagai agenda sebuah perguruan tinggi adalah pembentukan eksosistem keilmuan (Mulyono \& Wekke, 2018a). Sehingga memudahkan pimpinan dan warga kampus untuk mengkristalisasi budaya akademik. Termasuk perlunya untuk mengintegrasikan budaya akademik dengan tradisi keagamaan ((Mulyono \& Wekke, 2018b).

Pendidikan tinggi secara khusus perlu pemetaan. Tidak harus menjadikan perguruan tinggi semuanya berorientasi pada riset dan publikasi. Padahal dalam skala tertentu perguruan tinggi keislaman didirikan untuk menjadi bagian dari tafaquh fi al-din. Untuk itu dengan pengembangan ma'had 'aly, jangan sampai 60 perguruan tinggi keagamaan Islam negeri yang ada justru mengeyanmpingkan tugas pendidikan agama yang merupakan core kelembagaan. Dengan demikian perlu konvergensi antara pendidikan dan keterampilan penggunaan teknologi 
komunikasi dan informasi. Merebaknya informasi yang tidak signifikan dan cenderung fitnah disebabkan karena ketidakhadiran mahasiswa dan juga dosen untuk turut memperkaya content yang berbasis keilmuan di media sosial.

Pada akhirnya, perguruan tinggi keagamaan Islam perlu mengukuhkan keberadaan sebagai lembaga pendidikan Islam. Jangan sampai dengan melakukan pengembangan kelembagaan, justru meninggalkan misi awal pembentukan. Demikian pula dengan kecenderungan perguruan tinggi untuk menjadi perguruan tinggi riset. Padahal, pelbagai tipikal perguruan tinggi beragam untuk menjadi pilihan berkarya. Tidak semua perguruan tinggi mesti menjadi perguruan tinggi riset. Memungkinkan untuk mewujudkan perguruan tinggi yang lebih berorientasi pada masyarakat.

\section{Kesimpulan}

Perguruan tinggi keagamaan Islam di Indonesia mengembangkan kekhasan yang disesuaikan dengan lingkungan masing-masing. Sementara itu, juga mengadopsi program-program yang dapat dijadikan sebagai tolok ukur pengembangan studi Islam secara luas, seperti pembentukan lembaga mahad sebagai kewajiban mahasiswa untuk mengikuti program di tahun pertama. Dengan demikian, pada saat yang sama ada program-program yang dilaksanakan secara nasional namun pada yang sama dilaksanakan program yang hanya mewadahi aspirasi kawasan dan lokal yang dikembangkan sesuai dengan keperluan setempat.

\section{Daftar Pustaka}

Abdurrahman, M. (1995). Islam transformatif. Pustaka Firdaus.

Ali, A. M. (1988). Ilmu perbandingan agama di Indonesia. IAIN Sunan Kalijaga Press.

Ardinansyah, A., Tenrisau, D., Aslim, F., \& Wekke, I. S. (2018, July 21). Ketidakjujuran Akademik Dalam Pendidikan Tinggi. https://doi.org/10.31227/osf.io/tp9vg.

Arifin, S. (2014). Dimensi Profetisme Pengembangan Ilmu Sosial dalam Islam Perspektif Kuntowijoyo. TEOSOFI: Jurnal Tasawuf dan Pemikiran Islam, 4(2), 477-507. 
Azra, A. (1994). Jaringan ulama: Timur Tengah dan kepulauan Nusantara abad XVII dan XVIII: melacak akar-akar pembaruan pemikiran Islam di Indonesia. Mizan.

Buchori, M. (1994). Spektrum Problematika Pendidikan di Indonesia. Tiara Wacana Yogya.

Daulay, H. P. (2014). Pendidikan Islam dalam sistem pendidikan nasional di Indonesia. Kencana.

Fadjar, A. M., Zumar, D., \& Dja'far, S. F. (1999). Reorientasi Pendidikan Islam. Fajar Dunia.

Fuaduddin, B. (2002). Pendidikan Agama Islam, Dinamika Pemikiran Islam di Perguruan Tinggi: Wacana tentang Pendidikan Agama Islam/editor Fuaduddin \& Cik Hasan Bisri (Vol. 2002). Jakarata: Logos.

Hidayat, K. (2005). Islam, negara \& civil society: gerakan dan pemikiran Islam kontemporer. Paramadina.

Husaini, A. (2006). Hegemoni Kristen-Barat dalam studi Islam di perguruan tinggi. Gema insani.

Madjid, N. (1997). Tradisi Islam: Peran dan Fungsinya dalam Pembangunan di Indonesia. Jakarta: Paramadina.

Muhaimin, M. A. (2015). Manajemen Pendidikan (Aplikasinya dalam Penyusunan Rencana Pengembangan Sekolah/Madrasah). Prenada Media.

Mulyono, M., \& Wekke, I. S. (2018a). Academic and Culture Development Strategy Management for Islamic Higher Education In Indonesian. In IOP Conference Series: Earth and Environmental Science (Vol. 175, No. 1, p. 012163). IOP Publishing.

Mulyono, M., \& Wekke, I. S. (2018b). Religious and Academic Cultural in Technology Development on Islamic Higher Education of Indonesia. International Journal of Pure and Applied Mathematics, 119(18), 10931105.

Mulyono, M., \& Wekke, I. S. (2018c). Strategi Pembelajaran di Abad Digital. Yogyakarta: Penerbit Gawe Buku.

Nasution, H. (1975). Pembaharuan dalam Islam: Sejarah Pemikiran dan Gerakan. Bulan Bintang.

Queiroz, L. R. S., \& Figueiredo, S. (2016). 'The World Declaration on Higher Education for the Twenty-First Century'and perspectives for Music Education in Brazil. International Perspectives on Research in Music Education, 205.

Sabri, M., Ikhsan, M., \& Wekke, I. S. (2018). Pengalaman Paramadina sebagai Rumah Pengetahuan Berbasis Nilai-nilai Ketuhanan, Tradisi Hikmah, dan Ilmu Pengetahuan. TEOSOFI: Jurnal Tasawuf dan Pemikiran Islam, 8(2), 373-405.

Shihab, A. (1997). Islam inklusif: Menuju sikap terbuka dalam beragama. Diterbitkan Atas Kerja Sama an Teve Dan Penerbit Mizan.

Tilaar, H. A. R. (1998). Beberapa agenda reformasi pendidikan nasional dalam perspektif abad 21. IndonesiaTera.

Wekke, I. S. (2017). Arabic Teaching and Learning Material in Higher Education of Muslim Community North Sulawesi. Dinamika Ilmu, 17(2), 175-189. 
Wekke, I. S. (2018, May 4). Masa Depan Kajian Islam di Indonesia. International Student Conference on Islamic Studies (ISCIS), Manado, 21-23 September 2017, 185-193. https://doi.org/10.31227/osf.io/36tua.

Wekke, I. S., \& Sahlan, A. (2014). Strategy in creating school environment: lessons from high schools in indonesia. Procedia-Social and Behavioral Sciences, 143, 112-116.

Wekke, I. S., Hermawanto, A., \& Ashrori, M. (2016). Keberagamaan Mahasiswa Di Perguruan Tinggi Wilayah Minoritas Muslim. Ulul Albab, 17(2), 135. 